\title{
分婏前および分婏後における乳牛の心拍数と 熱発生量の関係について
}

\author{
福原弘紀・沢井利昭・山本禎紀 \\ 広島大学生物生産学部，福山市 720
}

(1982. 11. 29 受付)

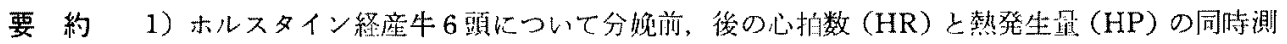
定在行ない，HR から HP を推定する方法について梌討した，2）分浼前に比べ，HR は分娩後に減少 し，HP は逆に，著しく增加するという特街ある变化を示した，3）各㮯体の HR からHPを推定する

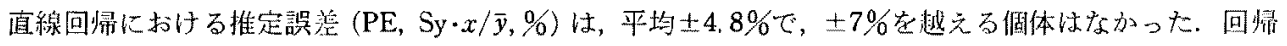
係数は, 分娩前, 後で買なり, 分娩前に比べ分娩後に大きな值を示した，4）HR, HP および回帰係数 における個体差は，分婏前，後の両期で認められた．5）キャリブレーションを行なわずに，分婏前お上

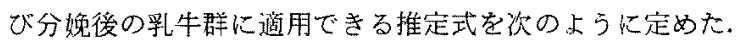

分娭前：Y=0.962+5.335X, Y=HP (kcal/W $\left.\mathrm{W}^{0.75} \cdot \mathrm{h}\right), X=\mathrm{RHR}(\mathrm{RHR}=\mathrm{HR} / 85.8)$

分娩後：Y=0.535+7.502X, Y=HP (kcal/W $\left.\mathrm{W}^{0.75} \cdot \mathrm{h}\right), \quad X=\mathrm{RHR}(\mathrm{RHR}=\mathrm{HR} / 70.9)$

85.8 および 70.9 は, それぞれ, 分婏前, 後における平凷基準 HR（分婏前, 後に打ける平均 HP に対

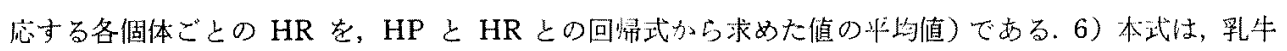

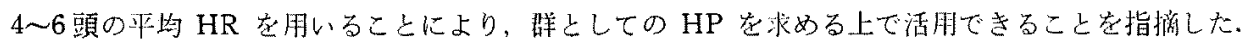

日畜会報， $54(9) ： 497-501 ， 1983$

家畜の飼養管理状態を生理的に解析するためには，経 時的に熟発生量(以下 HP と略す)を把握することが必 要であると考えられる，しかしながら放飼，放牧中の家 畜はもとより拘束した家畜に招いてい, 経時的にHPを 测定することは，極めて困嚾である。

心拍数 (HR) の連続測定值から HP を推定する方法 恃，間接的方法ではあるが，放飼や群飼されている個体 にも適用できる利点を持らこれまでに乳牛”のみなら

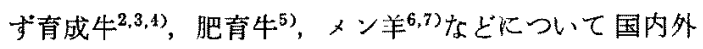
で広く検討されている。

しかしながら HR から HP を推定する万法を確立す るためには，循環生理に関する基礎的研究はるとより， 家畜の生理状熊や行動との関係, あるいは推定式に認め られる個体内敊よび個体間差などについて梌㣙を重小な ければならない，山本らは地，婎子牛と肥有牛の個体差 と群間差の解消法として, HR については相効心拍率 (RHR)を, HP については代謝体重 (M.B.S) 袁示に よる可能性を提示している.その後 YAMAMOTO $5^{4) は, ~}$ 去勢牛の長期にわたる HR とHP の連続测定から, 直線 回㷌式に個体差と日々間の個体差を琶め，基本的には，
利用時に個体ごとのキャリブレーションが必要であるこ とを指摘した。

本報で, 乳牛に括いて HR とHP の両者が著しく変 化すると考光られる分婏前，後の期間を選び，HRとHP の関係を調へ，雨期間に招ける HR の連続測定に基つ くHP の推定方法について検討した.

\section{試 験 方 法}

供試牛は，ホルスタイン経産牛 6 頭（年齡 3〜6藏）を 用いた. 試驗は，10〜12 月にかけて行ない，分婏前 24 2日,分娭後 20〜39日の乳牛について，それぞれ延べ 11回 と9回のキャリブレーションを実施した。

$\mathrm{HR}$ とHP の测定手順とその方法（キャリブレーショ ン). 1 山のキャリブレーションは，各牛 16 回の湘定か らなり，1日（09:30〜17:00)で行なった１6回の测定は

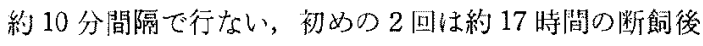
に当り，ての後各回とむ配合飼料 $1 \mathrm{~kg}$ と粗飼料を白青 播食させたのb行なった１回のキャリブレーションに 末ける飼料掑取量は，配合飼料 $9 \sim 14 \mathrm{~kg}$, 粗飼料として サイレージ 12〜22 kg あるいはへイレーシ 1.5〜6.5 kg, 
それに踤管とへイキューブで1.5〜6 kgであった。

HP の湘定は，アクリル板で留作したへッドケージを

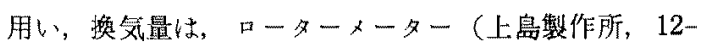
$1110 \mathrm{~A}$ ）を用いて，1分整に計㟟した。 ガス分析は，磁 気式 $\mathrm{O}_{2}$ 分析計 (富士電気, オキシマートII)を用い, 分 析值は，ナナログレコーダーで監視しながらマルチチャ ンネルデシタルレコーダー（タタダ理研, TR2711 M) に記録した， 1 回の測定は，5分以上とし，平均值は， ガス分析記録が安定した 5 分間の 20 秒毎の測定值から 求めた， $\mathrm{HP}$ の算出は， $\mathrm{O}_{2}$ 消費量のみから求める $\mathrm{Mc}$ LEAN $^{8}$ の式を用い，值仗 $\mathrm{kcal} / \mathrm{W}^{0.75} \cdot \mathrm{h}$ で裁示した。

HR は，ECGを多用途監視記録装置 (日本光電) で測 定し, 平均 HR は, ガス分析值とのタイムラグ1分を見
込み， 1 分旅 5 分間の值から算出した.

$$
\text { 結果 }
$$

1. 分婏前扣よび分娭嵝に怙ける HR と HP

分悗前，後の各キャリブレーションにおけるHR HP の平均值を表 1 に示した. HR とHPの個体差は分 俛前, 啳ともに浔められ, 特に HR の変動係数 (C.V.) は，いずれる10\%を越劣るものであった。しかし，HR は, 分㑑前に比へ，分婏啳に明らかに減少し，HPは逆 に著しく增加する㑯向を示した。

2. 分浼前および分娩後に祘けるHRとHPの関系 分始前, 後の HR 上 HP の直線回㷌係数, 推定誤差 $(\mathrm{PE}, \mathrm{Sy} \cdot x / y, \%)$, 相閶係数等を表 1 K, HR と HP の

Table 1. Values of the regression constants in the equation relating heat production to heart rate for six prepartum and postpartum Holstein cows

\begin{tabular}{|c|c|c|c|c|c|c|c|c|}
\hline $\begin{array}{l}\text { No. } \\
\text { of } 1 \\
\text { cow }\end{array}$ & Days & $\begin{array}{l}\text { Body } \\
\text { weight } \\
\text { (kg) }\end{array}$ & $\begin{array}{l}\text { Heart rate } \\
\text { (beats/ } \\
\text { min) }\end{array}$ & $\begin{array}{c}\text { Heat } \\
\text { production } \\
\left(\mathrm{kcal} / \mathrm{W}^{0.75} \cdot \mathrm{h}\right)\end{array}$ & $\begin{array}{l}\text { Regression } \\
\text { coefficient }(b) \dagger \\
\text { and } \mathrm{Sb}\end{array}$ & $\begin{array}{c}\text { Prediction } \\
\text { error }(\mathrm{PE}) \\
(\mathrm{Sy} \cdot x / \bar{y}, \%)\end{array}$ & $\begin{array}{l}\text { Intercept } \\
\text { at } \mathrm{HR}_{\text {(a) }} 60\end{array}$ & $\begin{array}{c}\text { Correlation } \\
\text { coefficient } \\
\text { (r) }\end{array}$ \\
\hline \multicolumn{9}{|c|}{ Prepartum } \\
\hline $21-1$ & 24 & 661 & 68.6 & 6.54 & $0.077 \pm 0.009$ & 5.1 & 5.88 & $0.917 * *$ \\
\hline-2 & 15 & 675 & 78.9 & 6.97 & $0.090 \pm 0.011$ & 5.5 & 5.25 & $0.914 * *$ \\
\hline-3 & 7 & 685 & 79.9 & 6.69 & $0.045 \pm 0.007$ & 3.7 & 5.77 & $0.869 * *$ \\
\hline 25 & 4 & 649 & 85.0 & 6.05 & $0.066 \pm 0.012$ & 5.3 & 4.44 & $0.799 * *$ \\
\hline $26-1$ & 18 & 695 & 113.2 & 6.13 & $0.044 \pm 0.005$ & 6.4 & 3.75 & 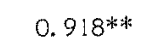 \\
\hline-2 & 9 & 700 & 96.1 & 5.68 & $0.061 \pm 0.007$ & 5.7 & 3.49 & $0.917 * *$ \\
\hline-3 & 2 & 700 & 93.7 & 5.55 & $0.053 \pm 0.007$ & 6.8 & 3.81 & $0.906 * *$ \\
\hline 31 & 15 & 690 & 75.3 & 6.00 & $0.086 \pm 0.007$ & 4.7 & 4.71 & $0.954^{* *}$ \\
\hline 33 & 6 & 625 & 73.4 & 6.42 & $0.059 \pm 0.008$ & 5.3 & 5.64 & $0.895 * *$ \\
\hline $36-1$ & 20 & 640 & 83.1 & 6.92 & $0.021 \pm 0.011$ & 4.3 & 6.45 & $0.455 \mathrm{NS}$ \\
\hline-2 & 15 & 650 & 77.2 & 6.60 & $0.062 \pm 0.010$ & 6.5 & 5.51 & $0.862^{* *}$ \\
\hline $\begin{array}{l}\text { Mean } \\
\pm S D\end{array}$ & & $\begin{array}{r}670.0 \\
\pm 26.3\end{array}$ & $\begin{array}{r}84.0 \\
+12.7 \\
\end{array}$ & $\begin{array}{r}6.32 \\
\pm 0.48 \\
\end{array}$ & $0.060 \pm 0.020$ & $\begin{array}{r}5.4 \\
\pm 0.9 \\
\end{array}$ & $\begin{array}{r}4.97 \\
\pm 0.99 \\
\end{array}$ & $\begin{array}{r}0.855 \\
\pm 0.189 \\
\end{array}$ \\
\hline \multicolumn{9}{|c|}{ Postpartum } \\
\hline 21 & 22 & 550 & 73.6 & 8.79 & $0.117 \pm 0.012$ & 3.9 & 7.20 & $0.938 * *$ \\
\hline $25-1$ & 23 & 505 & 82.0 & 8.58 & $0.115 \pm 0.026$ & 6.1 & 6.02 & $0.771 * *$ \\
\hline-2 & 32 & 500 & 80.5 & 9.22 & $0.080 \pm 0.014$ & 4.0 & 7.57 & $0.838 * *$ \\
\hline 26 & 27 & 549 & 73.8 & 8.17 & $0.162 \pm 0.028$ & 6.7 & 5.89 & $0.843^{* *}$ \\
\hline $31-1$ & 22 & 538 & 71.5 & 7.55 & $0.100 \pm 0.007$ & 4.3 & 6.39 & $0.965^{* *}$ \\
\hline-2 & 39 & 533 & 71.4 & 7.91 & $0.103 \pm 0.006$ & 3.0 & 6.73 & $0.975^{* * *}$ \\
\hline $33-1$ & 25 & 503 & 61.9 & 8.09 & $0.114 \pm 0.009$ & 3.5 & 7.90 & $0.956 * *$ \\
\hline-2 & 33 & 516 & 60.4 & 7.53 & $0.219 \pm 0.016$ & 2.5 & 7.43 & $0.963^{* * 4}$ \\
\hline 36 & 20 & 564 & 71.3 & 7.46 & $0.189 \pm 0.010$ & 2.4 & 5.32 & $0.981^{* *}$ \\
\hline $\begin{array}{l}\text { Mean } \\
\pm S D\end{array}$ & & $\begin{array}{l}528.7 \\
\pm 23.5^{* *}\end{array}$ & $\begin{array}{l}71.8 \\
\pm 7.2^{*}\end{array}$ & $\begin{array}{c}8.14 \\
\pm 0.61 * *\end{array}$ & $0.133 \pm 0.046 * *$ & $\begin{aligned} & 4.0 \\
\pm & 1.5 *\end{aligned}$ & $\begin{array}{l}6.72 \\
\pm 0.87 * *\end{array}$ & $\begin{array}{l}0.914 \\
\pm 0.076 \mathrm{NS}\end{array}$ \\
\hline
\end{tabular}

$* \mathrm{P}<0.05 * * \mathrm{P}<0.01 \quad \mathrm{NS}:$ not significant. tRegression equation, $Y=a+b(X-60), Y=\mathrm{HP}\left(\mathrm{Kcal} / \mathrm{W}^{0.75} \cdot \mathrm{h}\right)$, $X=$ HR (beats $/ \mathrm{min}$ ) 

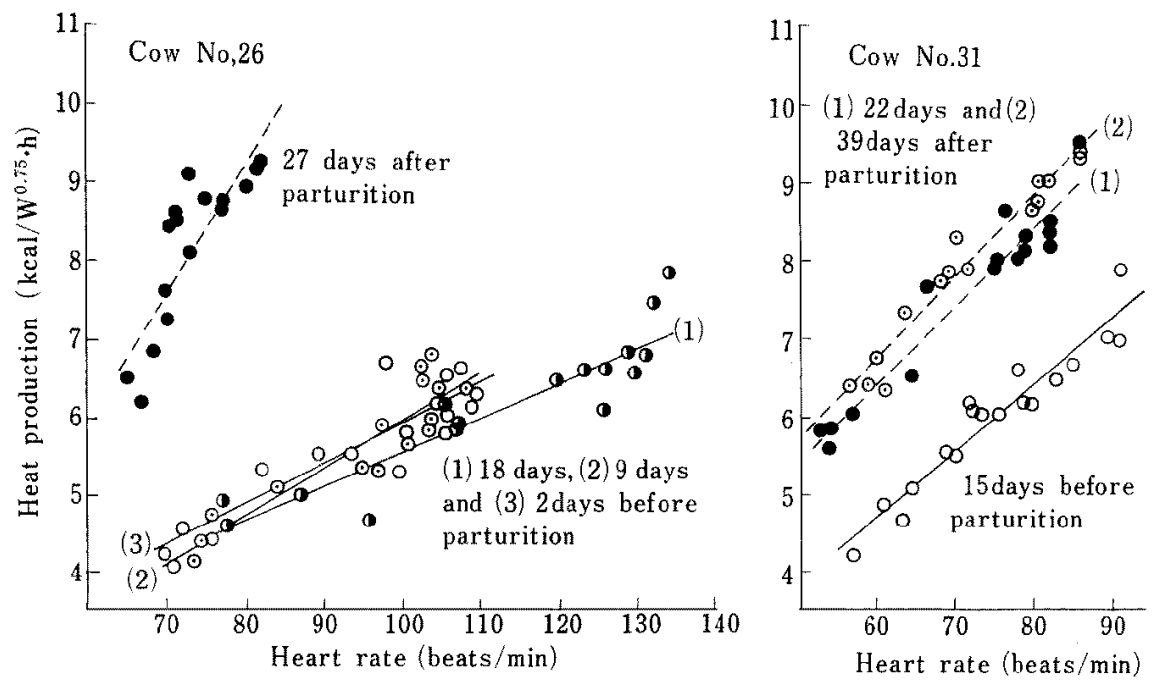

Fig. 1. Typical examples of the relationship between heart rate and heat production of prepartum and postpartum Holstein cows. Regression constants were shown in Table 1.

相関図を图 1 に例示した，相関倸数は，分娩前の一例老 除きすべて有意 $(P<0.01)$ であり，分婏前，後に違い は認められなかった。回熄係数は,分婏前で小さく分媸後 に大きな值を示した，推定誤差は，分婏前に比べ分娩後 でや小さい $(\mathrm{P}<0.05)$ 傾向にあり，その值は土2.4〜 $6.8 \%$ の螌围て，分婏前，後とも $\pm 7 \%$ 越光るものは一 例もなかった. しかしながら, 分婏前, 後区とも回㷌係数 のC.V.は，35\%に達する大きなもので，個体差の明ら かな存在が認められた。 また 2 回以上測定した例炇い て、日々間に比較的大きな違いが認めら九る例も娄った。

\section{考察}

一般に HR は，妊娠の進行に伴い漸增し，妊娠末期に 最高值に達し，分娩後減少する傾向を示す ${ }^{9,109}$ ，橋爪ら $2^{11)}$ 妊娠の進行に伴 5 HP の增加とともに, HR も同様 に变化することを示し，分婏後の HP は，娃娠末期の最 高值に近いと報告している。 今回の分娩前 24〜2日にわ える HRの测定においては，妊娠の進行に伴い增加する という傾向は，短期間であったためか諰められなかった が，分婏後のHR は，分婏前に比べ有意に減少すること を示した，一方，分婏後の HPは，分娩前に比べ 1.3 倍 と有意に增加していた，柴田らは ${ }^{12)}$ ，妊娠前の乾乳牛の $\mathrm{HR}$ 柱平均 50.5 回/分, HP は平均 $5.44 \mathrm{kcal} / \mathrm{W}^{0.75} . \mathrm{h}$ と して祘り，これに比べ今回の娃娠末期および泌乳期の HR と HP は，いずれも高いレベルにあった.

表1抢よび図1に例示したように, HR と HP の相関
関係任，分婏前の一例を除くといずれも高く, PE も全体 の平均は土4.8\%で，士7\%を越方る個体はなく，HR か ら HP を推定できる可能性を强く示すものであった。

回帰係数の分媿前，後の差は大きく，有意であった $(\mathrm{P}<0.01)$.これは，妊娠末期に打ける胎思の高い栄璧 要求, 泌乳期の活発な物質代射など, 妊娠進行, 分娩, 泌乳關始に伴う心肺機能の变化を反映し生したむのと考 えられるが，同時に妊娠末期と泌乳期では，少なくとも 别々の推定式を用いなりればならないことを示唆するる の上将竟られた。

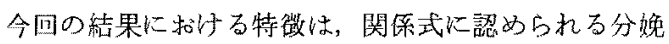
前, 後の明らかな違いと，両区妃抢けるHR，HP 打よび 回㷌係数炕認められる個体差であった。分浼前, 徣の明 らかな違いは，主としてHPKあり，両者の共通の推定 式を求めることはできないと考光られた，次炕各区内の 個体差を除くため，採食前の HR を基準にした RHR 法2,5)を用いたところ, PE は分娩前 \pm 10.9 , 分婏後士 10.5\%と，各個体ごとの值（表 1) をはるか比上回るた けでなく，実用限界とされる $\rightarrow た$.

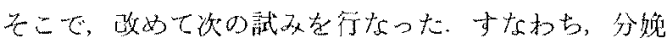
前拈上び分娭後区の和均 HP (分婏前 6.32，分婏後 8.14 $\left.\mathrm{kcal} / \mathrm{W}^{0.75} \cdot \mathrm{h}\right)$ に刘応する各㮯体ごとの HRを，それぞ れの回帰式から求めて基準 HR とした この基潐 HR に対するHR の比率 (RHR) を算出L, 分媸前, 後そ れぞれひと李と好してRHR とHPの関係を求めた。 


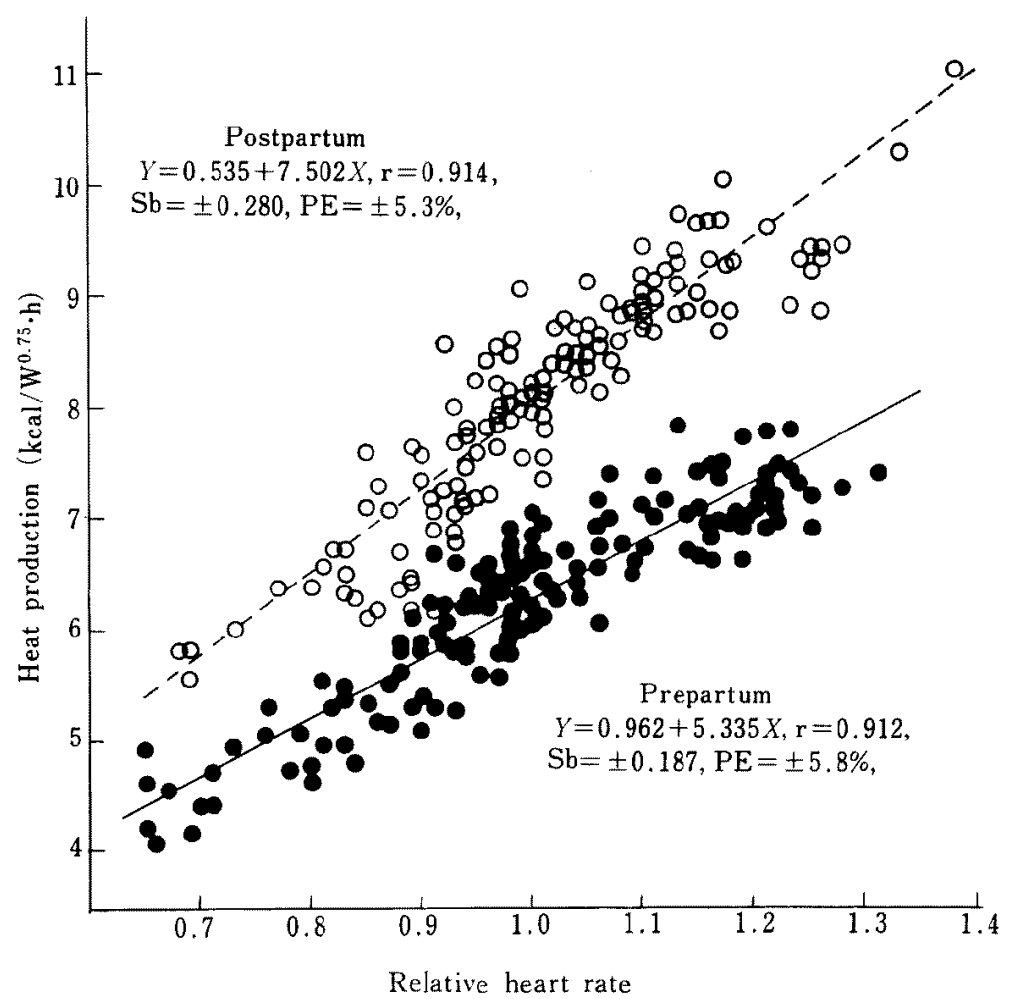

Fig. 2. The relationship between relative heart rate (RHR, X) and heat production (Y) of six pre-and postpartum Holstein cows. RHR is a ratio of HR to basic HR, which is calculated by substituting the mean value of $H P$ in pre- and postpartum groups into the regression equation for each cow (Table 1). The mean values of basic HR are 85.8 and 70.9 (beats $/ \mathrm{min}$ ) in pre- and postpartum, respectively.

RHR とHP の関係を图 2 亿示した。

分娩前，後て，それぞれひとまとめにした回㷌式のPE は、いずれ多土6\%を下回り，各個体ごとに求めた值(表1) に近く，推定式として栐めて有效であると考えられた。

また，各個体別の直線回帰以护方回㷌係数の C. V. は分婏前, 後とむ大きなものであった（分婏前平均13.2,
分婏後 11.2\%）が，本法による全体の回帰式の C.V. は, 分婏前 3.5 , 分娭後 $3.7 \%$ 小さく, 安定したもので あった。

本法を用いて, SHIBATA and MUKAI ${ }^{14}$ が 5 つの飼養条 件下で測定した泌乳牛の平均 HR から群の平均 HP を 推定したところ，表 2 に示す結果を得た。実測された平

Table 2. The difference between HP and estimated HP from HR in lactating Holstein cows

\begin{tabular}{cccccr}
\hline Treatment* & $\begin{array}{c}\mathrm{HR} * \\
\text { (beats/min) }\end{array}$ & RHR** & $\begin{array}{c}\mathrm{HP} *(\mathrm{~A}) \\
\left(\mathrm{kcal} / \mathrm{W}^{\mathbf{0 . 7 5}} \cdot \mathrm{h}\right)\end{array}$ & $\begin{array}{c}\text { Estimated HP(B)*** } \\
\text { from HR }\left(\mathrm{kcal} / \mathrm{W}^{\mathbf{0 . 7 5}} \cdot \mathrm{h}\right)\end{array}$ & $\begin{array}{c}\mathrm{B} / \mathrm{A} \\
(\%)\end{array}$ \\
\hline L C & 70.5 & 0.99 & 7.91 & 7.99 & 101.0 \\
H C & 66.3 & 0.94 & 7.90 & 7.55 & 95.6 \\
L M & 68.1 & 0.96 & 7.53 & 7.74 & 102.8 \\
H M & 69.4 & 0.98 & 7.81 & 7.88 & 100.9 \\
L R & 64.7 & 0.91 & 7.50 & 7.38 & 98.4 \\
\hline
\end{tabular}

Mean + SD $99.7 \pm 2.8$

*Cited from Shibata and Muka ${ }^{14}$. **RHR1 =70.9 (beats $/ \mathrm{min}$ ). ***Estimated values were calculated from equation for postpartum in Fig. 2. 
均 HP (100) に対与る推定 HP の比率は, 双均99.7士 $2.8 \%$ なり，高い精度で推定が可能であることを示し た.

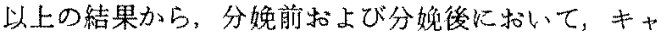
リブレーションを行なわずに，HR から HP を推定する には，HR の個体差を除くために少なくとも4〜6頭の 平均 HR を用小，平均基準 HR（分婏前 $85.8 \pm 18.8$ ，分

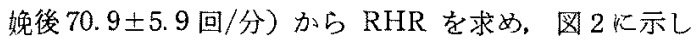
た推定式により，群としてのHPを算出する万法を提案 したいなお，平均基準 HR とは，先に述べた分婏前お よび分娩後に扣ける平均HPを朋いて，各個体ごとに算 出した基準 HR の平均俌である。

本研究を行ならに当り，種々ご配感いただきました広 島大学付属農場, 赤木英二, 塩飽忠博雨技官心心的感 竧いたします。

$$
\text { 文献 }
$$

1）山本襀紀・古本 史，日畜会跟，51：541-547. 1980.

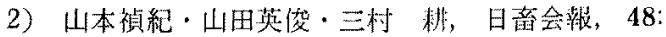
131-137. 1977.

3) Holmes, C. W., D. B. Stephens and J. N. Toner, Livestock Prod. Sci., 3: 333-341. 1976.

4) Yamamoto, S., J. A. Mclean and A. J. Downie, Br. J. Nutr., 42: 507-513. 1979.

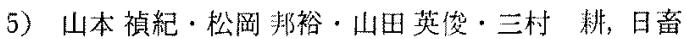
会報，48：138-143. 1977 .

6) Webster, A. J.F., Br. J. Nutr., 21: 769-785. 1967.

7) Brockway, J. M. and E. H. McEwan, J. Physiol., 202: 661-669. 1969.

8) Mclean, J.A., Br. J. Nutr., 27: 597-600. 1972.

9) Dukes, H. H., The physiology of Domestic Animals. 142-145. Comstock Publishing Associates. New York. 1964.

10）山本祜紀，栄㿥生理砋究会報，23：59-73，1980.

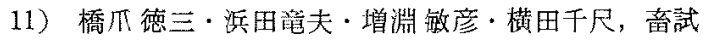
研報，3: 121-123，1963.

12）柴田正貴-向居彰夫, 日畜会報，53: 33-38. 1982.

13) Brockway, J. M., Proc. Nutr. Soc., 37: 13-19. 1978.

14) Shibata, M. and A. Mukal, Jpn. J. Zootech. Sci., 50: 630-637. 1979.

\title{
The Relationship between Heart Rate and Heat Production of Dairy Cows in Prepartum and Postpartum
}

\author{
Koki Funuhara, Toshiaki Sawai and Sadaki Yamamoto \\ Department of Animal Science, Hiroshima \\ University, Fukuyama-shi 720
}

1. Heart rate (HR) and heat production (HP) were measured simultaneously using a head cage for six pre-and postpartum Holstein cows. 2. HR after parturition decreased as compared with prepartum, but conversely, HP increased significantly after parturition. 3. The regression of $\mathrm{HP}$ on $\mathrm{HR}$ was significant in all cases. The accuracy of prediction error $(\mathrm{PE}, \mathrm{Sy} \cdot x)$, expressed as a percentage of $\bar{y}$ was $\pm 4.8 \%$ (range $\pm 2.4 \sim 6.8 \%$ ). However. there were wide differences in the values of the regression constants between pre- and postpartum groups and also among individuals of the same group. 4. For pre- and postpartum dairy cows, the following equations for the estimation of HP from HR were determined to eliminate the need to calibrate for each individual cow.

$$
\begin{aligned}
\text { Prepartum: } Y=0.962+5.335 X, Y=H P\left(k c a l / W^{0.75} \cdot h\right), X=R H R(R H R=H R / 85.8) \\
\text { Postpartum: } Y=0.535+7.502 X, Y=H P\left(k \mathrm{kal} / W^{0.75} \cdot \mathrm{h}\right), X=R H R(R H R=H R / 70.9)
\end{aligned}
$$

The mean values of basic $H R$ are 85.8 and 70.9 (beats/min) in pre- and postpartum, respectively. 5. A better way to estimate HP from the above linear regression would be to us a mean group $\mathrm{HR}$ with a minimum of $4 \sim 6$ cows, in order to correct for differences in individual $\mathrm{HR}$. 